\title{
Role of epidermal growth factor receptor and microbial infections in polycystic kidney disease
}

\author{
Orzechowska $\mathrm{K}^{1}$ *, Muhammad $\mathrm{SN}^{2}$, Mokamil $\mathrm{H}^{3}$ \\ *Corresponding author: \\ Orzechowska K, Coventry University (CU), \\ Dept. of Health and Life Sciences - Coventry UK \\ Research Intern, The Renal Patient Support Group (RPSG) \\ - Bristol UK. \\ Email: orzechok@cu.coventry.ac.uk $\underline{\text { ORCID }}$
}

\section{Information about the article:}

Received: July 12, 2021

Accepted: Nov 7, 2021

Published online: Dec 31, 2021

Cite this article:

Orzechowska K, Muhammad SN, Mokamil H. Role of epidermal growth factor receptor and microbial infections in polycystic kidney disease. Journal of Biomedical Sciences. 2021; 8(2):65-73

\section{Publisher}

Nepal Health Research Society, Bahundhara -6, Gokarnesowor Municipality, Kathmandu, Nepal eISSN 2382-5545, ISSN 2676-1343 (Print)

(C) The Author(s). 2021

Content licensing: CC BY 4.0

\begin{abstract}
Background

Autosomal Dominant Polycystic Kidney Disease (ADPKD) is a frequently inherited diseases associated with the presence of fluid-filled cysts. Epidermal Growth Factor Receptor (EGFR) plays role in cysts development
\end{abstract}

\section{Material and methods}

The following tools (PubMed, PubMed Central, Medline Search Engine, Locate and Google Scholar) were used in literature search. Key words used to search for relevant literature are: Polycystic Kidney Disease, Epidermal Growth Factor Receptor, Tyrosine Kinase Inhibitor, Renal Cyst Formation and Renal Cyst Infection. The studies beyond 10 years were not included in present study.

Analysis: The cross-examination of research papers allowed to analyse literature around role of EGFR in ADPKD pathophysiology, EGFR TKI as treatment of ADPKD and role of microbial cyst infections in disease progression.

\section{Results}

There is a small body of literature that look at EGFR, Tyrosine Kinase Inhibitor (TKI) and cyst infection in ADPKD over the last decade. The 'crosstalk' between Src and EGFR was observed to have an impact on cyst development and progression. Therefore, the combined treatment with different compounds can be a desirable approach in the treatment of ADPKD. There has been observed relationship between cyst infections, decrease in kidney function and PKD gene mutation. Endotoxins of Gram-negative bacteria could be involved in disease development.

\section{Conclusion}

The understanding of mechanisms of ADPKD and several cancers has led to the identification of molecular targets, and one of these is EGFR. The further study could establish the role of endotoxin in ADPKD development and its interaction with EGFR.

Keywords

PKD, TKI, Kidney Care, EGFR, Microbiology, Science 


\section{Background}

Autosomal Dominant Polycystic Kidney Disease (ADPKD) is one of the most frequent inherited disorder in humans influencing 60,000 patients in the UK, and an estimated 10 million worldwide [1]. It is estimated that ADPKD affects 1 per 400 - 1000 people [2]. The development of ADPKD is associated with mutations in one of the following genes PKD1 or PKD2 [3, 4].

A significant characteristic of this disease is a presence of fluid-filled cysts [5, 6] and enlargement of the Total Kidney Volume (TKV) [7]. Evidence suggests that TKV is crucial in the estimation of kidney cyst burden and disease progression $[8,9]$. Progressive cyst formation and reduction of renal functions often lead to End-Stage Renal Disease (ESRD) which appears when the patient reaches the fourth or fifth decade of life [5].

The evidence suggests that typical characteristic of ADPKD in humans are an expansion of the renal collecting tubules and cyst formation originate from the localised proliferation [10]. Research in this area has eluded that kidney cysts contain fluid in which occurs active ligands for the Epidermal Growth Factor Receptor (EGFR) such as Epidermal Growth Factor (EGF), Transforming Growth Factor- $\alpha$ (TGF- $\alpha$ ) and Heparin-binding EGF (HB-EGF) [11].

Cyst infection is among the most crucial factors for ADPKD progression and decrease in kidney function. Urinary Tract Infections (UTIs) are a frequent and severe complication of ADPKD and had been observed in 30-50\% of ADPKD patients [12]. The diagnostic criteria and methods of treatment options for cyst infection are not well defined [13]. It has been observed that Escherichia coli is the most often causative agent of cyst infections [14]. The endotoxin of Gram-negative bacteria has a vital role in the dysfunction of some organs, including kidneys [15]. Since the cyst infections are associated with an ADPKD progression, there is a need for developing a novel treatment $[13,16]$.

Present research studies on EGFR Tyrosine Kinase Inhibitors (TKIs) do not state if there is associated improvement in patients' health and demonstrate effects on patient outcome. Therefore, an understanding of pharmacodynamic and pharmacokinetic of TKIs in patients who have cancer can allow a better comprehension of differences in overactive EGFR TK in renal cysts and cancer. There is a need to find out how TKI can be effectively used in the treatment of ADPKD.

This review summarises the recent advances in mechanisms of overexpression of EGFR in the formation of renal cysts and kidney enlargement, potential of TKIs and role of microbial infections in development and progression of ADPKD.

\section{Material and methods}

This research seeks to systematically reviewed literature surrounding EGFR and cyst infections. The literature reviewed in this research was found using PubMed, PubMed Central, Medline Search Engine, Locate and Google Scholar. Key words used to search for literature are listed in Table 1 (Supplement 1).

The key words from Table 1 helped identify research papers containing context relevant to objective. Additional key terms were categorised into four search groups as highlighted in Table 2 (Supplement 2), and these were used to collate papers more specifically. The inclusion and exclusion criteria for this project are listed in Table 3 (Supplement 3). The criteria was helpful in identifying, cross-examine and investigate literature for this study. All literature included was in the English language.

As evidence in Table 1 (Supplement 1) and 2 (Supplement 2), a total of 136 research papers were identified. The literature reviewed in this study included cohort studies, systematic reviews and clinical trials surrounding EGFR TK, EGFR TKIs and microbial infections in ADPKD. Although the studies included in this research contained the keys words, many of the papers were irrelevant, (i.e., they focused on cyst formation in autosomal recessive form of PKD, or cyst formation in other organs, including liver and pancreas).

A minority of the reviewed studies focused on EGFR TK and EGFR TKI and were carried out on animal cell lines or animals (mice, rats). The studies beyond 10 years were not included in this investigation.

The literature reviewed in this project was cross-examined using the Critical Appraisal Skills Programme (CASP), according to type of paper (i.e., qualitative, quantitative, systematic reviews, and case-controlled studies). The CASP helped analyse literature considering the following questions:

- $\quad$ Are the results of the study valid?

- What are the results?

- Will the results help locally? [17].

\section{Analysis}

The cross-examination of research papers led to the creation of three main themes.

\section{These themes include:}

Theme 1: Role of Epidermal Growth Factor Receptor in ADPKD pathophysiology

Theme 2: Epidermal Growth Factor Tyrosine Kinase Inhibitor as treatment of ADPKD

Theme 3: Role of microbial cyst infections in disease progression

The literature has been organised across three themes in order to conduct systematic analysis on role of EGFR, EGFR TKI and microbial infections in ADPKD. 


\section{Review of literature}

\section{Theme 1: Role of Epidermal Growth Factor Receptor in ADPKD Pathophysiology}

Epidermal Growth Factor Receptor (EGFR) belongs to a family of ErbB receptors which include ErbB1 (EGFR), ErbB2 (HER2), ErbB3 (HER3) and ErbB4 (HER4). These transmembrane receptors and ligands are involved in cell proliferation, development and cell differentiation. The binding of ligands results in the stimulation of intracellular signalling pathways [18, 19]. There is a relatively small body of literature that is concerned with EGFR in ADPKD in the last 10 years. Much of the literature on EGFR pays particular attention to cancer development. The available research studies do not show on one model of pathologic cyst formation in ADPKD.

One well-known study cited in research on EGFR is that of Richards et al. (1998) [10], who provided strong evidence for a role of EGFR in stimulating tubular epithelial cell proliferation and cyst creation. It has been investigated that in human and animal ADPKD models, cell polarity is disturbed, and EGFR expression is increased. The disturbed polarity of cells leads to overexpression and mislocalisation of EGFR to the apical membrane of the epithelia $[19,20]$.

In a study conducted by Aguiari et al. (2013) [21], it was observed that EGFR stimulates cell proliferation in ADPKD through a mechanism involving the consecutive initiation of RAS, RAF-1, MEK and ERK signalling. It was investigated that EGFR signals converge with cAMP at the same signalling pathway, and this leads to stimulation of ERK kinase. In cystic cells, the apical plasma membrane is involved in changed localisation of EGFR, and this plays an additional role in cyst enlargement [21].

A study conducted by Elliott et al. (2011) [22] studied the role of Src in cyst formation of renal epithelial cell-matrix adhesion and cell proliferation. The authors found that modifications in ErbB- and Src- dependent signalling can directly affect the expression of proteins in the ErbB/RAS/RAF/MEK/ERK pathway. It was observed that Pkd1 gene loss elevated Src activity. The increased activity and interactions of Src-ErbB signalling promotes the increased fibrosis that likely has a meaningful influence on cyst development and disease progression [22].

Moreover, the localisation of EGFR at the cell cilium in normal cells have been lost in ADPKD cells as a result of disturbed cell functionality [23]. A study by Coaxum et al. 2014 [23] investigated the signalling pathways of EGFR in PKD and factors which has a function in cilia cells proliferation. It was found that EGF was expressed in PKD cell lines orpk cilia (+) and orpk cilia (-). The loss of cilia was associated with mis-localisation of EGFR to the apical membrane in orpk collecting duct cells [23].

The overexpressed activity of EGFR was observed in ADPKD and different types of cancers. However, EGFR is not mutationally activated in ADPKD, as is the case in many types of cancers (breast, colon and prostate) [18]. In many cases of cancer, EGFR phosphorylation is observed, which usually appears to be a response to ligand stimulation [24].

\section{Theme 2: Epidermal Growth Factor Tyrosine Kinase Inhibitor as a potential treatment of ADPKD}

Several studies investigated that, pharmacological inhibition of EGFR TK activity can improve renal function, reduce the cystic burden and initiates multiple downstream signalling pathways [18, 22, 23]. The study by Sweeney et al. (2017) [25] found that Tesevatinib demonstrated clinical activity against EGFR, ErbB2 and Src in murine PKD. The clinical study of Sweeney and colleagues 2017 [25] investigated that Tesevatinib might decrease cyst development and disease progression in ADPKD patients.

In relation to study results of Sweeney et al. (2017) [25] the clinical trial on Tesevatinib was conducted. The clinical Phase I trial of Tesevatinib assessed the plasma pharmacokinetics, safety and maximum tolerated dose of the drug. The results suggested reduced tolerability of high dosage of $150 \mathrm{mg}$ daily, with side effects such as skin rash, cardiac abnormalities and diarrhoea. However, a daily dose of 50mg was well tolerated. Patients who completed the 24months of treatment during the Phase I trial continued to receive the initial dose during the Phase II trial. The Phase II trial focused on the efficiency and safety of Tesevatinib at the dose of $50 \mathrm{mg}$ a day in relation to placebo. The monitoring of long-term safety, influence on impaired kidneys and alteration in estimated Glomerular Filtration Rate (eGFR) were evaluated. The trial was completed in January 2021. The final study results were not publicly released at the time of preparation of this review (Study Identifier: NCT01559363) [26].

In the study conducted by Elliott et al. (2011) [22], it was found that Bosutinib (SKI-606) inhibits cyst-lining epithelial cell proliferation, decreases cell-matrix adhesion in vitro and can reduce the size and number of renal cysts in a PKD1 rodent model of ADPKD in vivo. After the successful completion of the study by Elliot et al. (2011) [22], (Tesar and colleagues) [27] conducted a Phase II trial of Bosutinib versus placebo in ADPKD. This trial evaluated the safety and efficacy of Bosutinib in ADPKD patients. The participants were divided into three groups, first received placebo (56 participants), second - 200mg/d Bosutinib (58 participants) and the 3rd group received a daily dose of $400 \mathrm{mg} / \mathrm{d}$ Bosutinib (31 participants). The study was conducted for 24 months. In the third group of participants, only 3 out of 31 patients completed the treatment. This study demonstrated that SKI-606 could reduce the kidney growth rate in patients with ADPKD, and was approximately $100 \mathrm{ml}$ smaller with Bosutinib 200mg/d than placebo. Participants received 200mg Bosutinib and had a similar result of eGFR to placebo. The increase in eGFR was recorded in patients who received a high dose of Bosutinib [27]. At the end of treatment with this drug, the eGFR was checked. 


\section{Theme 3: Role of microbial cyst infections in disease progression}

The progressive renal cyst development and enlargement of kidneys put ADPKD patients at high risk of UTI and cyst infection [12]. Despite this, there is a relatively small body of literature that is concerned with the effects of infections in ADPKD. It was reported by Idrizi et al. (2011) [28] that cyst infection is a severe complication and leads to hospitalisation approximately $9 \%$ of ADPKD patients [28]. Studies indicated that ADPKD patients after kidney transplantation are at greater probability for kidney infections than the general population [29]. Additionally, UTIs are more recurrent in women than in men (female $68 \%$ and male 19\%) [28].

Recent evidence suggests that most frequent causative factors of infection in ADPKD are E. coli, Klebsiella spp. and Enterococcus spp. and these pathogens were more recurrently isolated from cyst fluid cultures than blood cultures $[14,30]$. Several lines of evidence suggest that fungal infections of cysts are recognised as a rare event in ADPKD. Over the past decade, only two case studies identified fungal infections in renal cysts [31, 32]. The potential fungal causative agent is Candida albicans. The risk factors associated with fungal infection in ADPKD are the use of a catheter, Haemodialysis (HD) therapy and oral admission of immunosuppressant [31].

Several studies had identified a link between infections and disease progression [12, 30]. Recent evidence suggests that asymptomatic pyuria and UTI can have an impact on renal functions in ADPKD patients [12, 30]. However, the generalisability of much published research on this issue is problematic. A study by Eroglu et al. (2019) [12] suggested that there might be a relationship between UTIs, kidney function, TKV and PKD gene mutation. It was established that ADPKD patients with UTI had lower eGFR than those without UTI (64.9 versus 89.5). TKV remained significantly increased in ADPKD patients burdened with UTI versus ADPKD patients without infection $(950 \mathrm{ml}$ vs $345 \mathrm{ml})$. Also, the presence of PKD1 mutations was associated with increased TKV in ADPKD. The investigations of TKV in ADPKD burdened with infections can help in the prediction of multiple UTIs and disease progression [12].

The retrospective case-control study from (2013) explored the effect of asymptomatic pyuria and UTI on renal functions in ADPKD patients. Asymptomatic pyuria was observed in approximately $1 / 3$ of the ADPKD patients [30]. It was detected that chronic asymptomatic pyuria was correlated with an increased occurrence of persistent UTI and ESRD. Data from this study also suggested that patients who experienced pyuria showed a greater prevalence of UTI in the future [30]. Although urine culture was performed in less than $5 \%$ of the patients with asymptomatic pyuria, this put them on the increased risk of wrong diagnosis and development of multidrug resistance $[13,30]$.
Frequent causative agents of cyst infection are Gram (-) bacteria from the intestinal flora [14, 29]. Gram-negative bacteria possess endotoxin in the cell walls, which play a crucial function in the pathogenesis of multi-organs [15]. There is limited research that explores influence of endotoxin on cyst infection. Publications that concentrate on endotoxin in PKD appeared about two decades ago [33]. However, in a review of Virzi et al. (2017) [15], it was identified that endotoxin could induce renal dysfunction in humans. Also, systemic endotoxin administration showed an increased number of different biologically active mediators, which appeared to be "responsible for the impairment of renal blood flow, glomerular filtration rate (GFR), and tubular dysfunction" [15]. Exposure to excessive levels of endotoxin and bacteria remains closely related to short-term complications, including pyrogenic reactions and septicaemia. Ibrahim et al. (2018) [34] identified that circulating endotoxins increase in Chronic Kidney Disease (CKD) stages 4 and 5. Also, a significant association between a modification of endotoxin level and age in HD patients was identified. It was identified that HD patients had a greater level of serum endotoxin [34].

\section{Discussion}

The present research set out to assess the importance of EGFR in cyst formation and investigate the potential of EGFR TKIs in the treatment of ADPKD. Also, this study reviewed the literature around influence of cyst infection on development and progression of ADPKD. It was observed that there is a relatively small body of literature concerned with EGFR and cyst infection in the last 10 years. This review asserts that there is a further need for research on EGFR as a therapeutic target in the development of renal cysts on human or/ and human cell lines. In the last 10 years of the 24 studies around EGFR in ADPKD, only two studies were conducted on humans [26, 27]. The positive data on EGFR inhibition with human interventions in nephrology are remarkably limited [19]. However, possible explanation for this might be that available regulations require researchers to test drugs on Safety Animal Models before the drugs are tried on humans.

A strong relationship between EGFR and Src and its impact on cyst development and progression has been reported in animal model of ADPKD. The observation of EGFR and Src activity prompted scientist to use both inhibitors in slowing down the progression of ADPKD [41]. Research by Elliott et al. (2011) [22] demonstrates that targeting EGFR and Src signalling pathways with SKI-606 had a good outcome in controlling cyst formation in rodent models. It was also suggested that targeting different drug might have altered effectiveness depending on the gene (PKD1, PKD2) mutation or level of dependence on EGFR stimulation [35, $36]$. In the past 20 years, there has been only eight studies conducted on the animal model of ADPKD. These studies highlighted successful results on the inhibition of EGFR and Src. It can therefore be implied that inhibitors of EGFR 
and Src could be a potentially used in treatment of ADPKD as combined treatment with two or more different inhibitors can independently block more signalling pathways [35].

The present study confirms that EGFR is linked with several types of solid tumours based on the literature reviewed earlier which indicated that there is a similarity in overexpression of EGFR and downregulation [18, 24]. The use of TKI in therapy of cancer is a dynamic changing area in targeted drug development. TKIs have the advantage of minor side effects and proven high effectiveness in highly invasive cancers. Potentially the same inhibitors used in cancer therapy can be effective at lower doses in ADPKD treatment [35]. Moreover, a study by Parker et al. (2020) [18] suggests that treatment of ADPKD remains challenging and is associated with limitations arising from the nature of this disease. In ADPKD, the kidney functions are impaired, which add additional risks in drug doses. Drug therapy for ADPKD must, therefore be well-tolerated over long-time use [18] and drug-drug interactions must be taken into consideration. Currently, Tolvaptan is an only available option for treatment of ADPKD recommended by National Institute for Health and Care Excellence (NICE 2015) and approved by US Food and Drug Administration [41].

The present study also established that cyst infection is a common complication in ADPKD. Surprisingly, the diagnostic criteria and methods of treatment options are limited and not well defined [31]. Studies conducted by Suwabe et al. (2015) [14] and Hwang et al. (2013) [30] pointed that a common causative agent of cyst infection is E. coli. In the last decade, only two case studies were reported relating to fungal infections in renal cysts [31, 32]. The most apparent finding that emerged from the analysis of available literature was that UTI in ADPKD most often affects women than men. Chronic cyst infection and presence of high endotoxin levels can have an influence on kidney function worsening. It was also suggested by Hwang et al. (2013) [30] that chronic asymptomatic pyuria is common in ADPKD patients and is associated with an increased incidence of persistent UTI. Therefore, it should be recommended to monitor ADPKD patients closely.

The present study conclude that chronic cyst infection and presence of high endotoxin levels can have an influence on kidney function worsening. The studies [37, 30] have demonstrated that the environmental factors, mutation or damage of the PKD gene were considered to be involved in local metabolic stress and the actions of microbes and toxins. It was observed that ADPKD patients are at higher risk of endotoxins influence originated from the diet and gut microflora. Endotoxin is a nephrotoxic inflammatory substance which was observed in urine and cyst fluid of PKD patients [37, 30]. Humans are exposed to endotoxin and clear them through the urinary system. Therefore, a failure in clearing of endotoxins from obstructed tubules leads to it retention and development of persistent infections [37]. It was recognised that persistent inflammation can stimulate EGFR and endotoxin-activated cell proliferation [38].

It is possible; therefore, that asymptomatic pyuria or presence of endotoxin could be a direct cause of cystogenesis. Available hypotheses suggest the origination and development of renal cysts in ADPKD patients. For example, Tan et al. (2011) explained that cysts formation and variability in size depends on the two-hit model. The first hit is a germline mutation, which is necessary but may not lead to abnormalities in kidney structures. The second hit is a somatic mutation of the normal tubular cell and inactivates of the normal PKD1 or PKD2 alleles [39, 40]. Therefore, it could be suggested that continuous inflammation or presence of endotoxin is a third hit in ADPKD and may lead to the cellular proliferation and cyst development [30]. However, this needs to be investigated further.

It is crucial to establish the most appropriate treatment of renal cyst infections in ADPKD. The correct diagnosis and treatment of UTIs decreases the frequency and reduces ADPKD progression. However, antibiotic therapy in ADPKD is associated with a high rate of failure [16]. The great exposures of ADPKD patients to antibiotics put them at increased risk of infection with multidrug resistance (MDR) organisms [13]. However, the data related to MDR in ADPKD are minimal. There is a need for novel strategies such as dual RNA-seq and Single-cell RNA sequencing (scRNA-seq), which can provide an understanding of the molecular relationship between host and pathogen. The novel targeted therapies can be helpful in treatment of infectious complications in ADPKD patients. Hopefully this therapy would be successful in patients with PKD. However, not many studies were done in this area.

\section{Conclusion}

The understanding of mechanisms of ADPKD and several cancers has led to the identification of molecular targets, and one of these is EGFR. EGFR stimulates cell proliferation in ADPKD through a mechanism involving activation of the signaling cascade. The increased activity and interactions of EGFR and Src play a crucial role in increased cell growth and fibrosis.

The interactions between TK could be possibly used to treat ADPKD with a combination of inhibitors. ADPKD patients are burdened by persistent UTI and cyst infections. There is a need for further study on the role of Gram-negative bacteria (e.g., E. coli) and endotoxin in ADPKD development and progression.

\section{Abbreviations}

ADPKD - Autosomal Dominant Polycystic Kidney Disease

cAMP - cyclic adenosine monophosphate

CASP - Critical Appraisal Skill Programme

EGF - Epidermal Growth Factor

EGFR - Epidermal Growth Factor Receptor

eGFR - estimated Glomerular Filtration Rate 
ERK - extracellular signal-regulated kinase

ESRD - End Stage Renal Disease

HB-EGF - Heparin-binding EGF

HD - Haemodialysis

MDR - Multidrug resistance

MEK Mitogen-activated protein kinase

NICE - National Institute for Health and Care Excellence

PKD - Polycystic Kidney Disease

RAF-1 - proto-oncogene

RAS - named from Ras sarcoma virus

TGF- $\alpha$ - Transforming Growth Factor- $\alpha$

TKI - Tyrosine Kinase Inhibitor

TKV - Total Kidney Volume

UTI - Urinary Tract Infection

\section{Authors' contribution}

a. Study planning: OK, MSN, MH

b. Review of literature: OK

c. Manuscript writing: OK

d. Manuscript revision: OK, MSN, MH

e. Final approval: OK, MSN, MH

f. Agreement to be accountable for all aspects of the work:

$\mathrm{OK}, \mathrm{MSN}, \mathrm{MH}$

\section{Funding}

No funding was obtained for this study.

\section{Availability of data and materials}

All data underlying the results are available as part of the article, and no additional source data are required separately as additional material for this research.

\section{Competing interests}

None declared.

\section{Publisher's Note}

NHRS remains neutral with regard to jurisdictional claims in published maps and institutional affiliations.

The publisher shall not be legally responsible for any types of loss, actions, claims, proceedings, demand or costs or damages whatsoever or howsoever caused arising directly or indirectly in connection with or arising out of the use of this material.

\section{Author information}

${ }^{1}$ Orzechowska K, Coventry University (CU),

Dept. of Health and Life Sciences - Coventry UK

Research Intern, The Renal Patient Support Group (RPSG) Bristol UK. ORCID

${ }^{2}$ Muhammad SN, Academic Scientist, University of the West of England (UWE), Dept. of Health and Applied Sciences Bristol UK ORCID

${ }^{3}$ Mokamil H, Coventry University (CU), Dept. of Health and Life Sciences - Coventry UK ORCID

\section{References}

1. Wilson PD. Therapeutic targets for polycystic kidney disease. Expert Opin. Ther. Targets. 2016; 20(1): 35-45. https://doi.org/10.1517/14728222.2015.1083979

2. Potts JW, Mousa SA. Recent advances in management of autosomal-dominant polycystic kidney disease. Am. J. Health-Syst. Pharm. 2017; 74(23): 1959-1968. https://doi.org/10.2146/ajhp160886

3. Torres VE, Harris PC, Pirson Y. Autosomal dominant polycystic kidney disease. Lancet 369. 2007; (9569): 1287-1301. https://doi.org/10.1016/S0140-6736(07)60601-1

4. Thivierge C, Kurbegovic A, Couillard M, Guillaume R, Cote O, Trudel M. Overexpression of PKD1 causes Polycystic Kidney Disease. Mol. Cell. Bio. 2006; 26(4): 1538-1548. https://doi.org/10.1128/MCB.26.4.1538$\underline{1548.2006}$

5. Paul BM, Heuvel GBV. Kidney - Polycystic Kidney Disease. Wiley Interdiscip. Rev. Dev. Biol. 2014; 3(6): 465-487. https://doi.org/10.1002/wdev.152

6. Lanktree M, Haghighi A, di Bari I, Song X, Pei Y. (2020) Insights into Autosomal Dominant Polycystic Kidney Disease from Genetic Studies. Clinical Journal of the American Society of Nephrology. [internet], 2020 [ 2020/7/30]; 16: 110.

https://doi.org/10.2215/CJN.02320220

7. Narita I. Estimating Growth Rate by a Single Measurement of Kidney Volume in ADPKD. Kidney Int. 2020; 5(9): 1383-1384. https://doi.org/10.1016/j.ekir.2020.06.035

8. Grantham JJ, Torres VE, Chapman AB, GuayWoodford LM., Bae KT., Kind BF et al., (2006) Volume Progression in Polycystic Kidney Disease. N Engl J Med. 2006; 354: 2122-2130. https://doi.org/10.1056/NEJMoa054341

9. Chapman AB, Devuyst O, Eckardt K-U, Gansevoort RT, Harris T, Horie $\mathrm{S}$ et al. Autosomal Dominant Polycystic Kidney Disease (ADPKD): Executive Summary from a Kidney Disease: Improving Global Outcomes (KDIGO) Controversies Conference. Kidney Int. 2015; 88(1): 17-27. https://doi.org/10.1038/ki.2015.59

10. Richards WG, Sweeney WE, Yoder BK, Wilkinson JE, Woychik RP, Avner ED. Epidermal Growth Factor Receptor Activity Mediates Renal Cyst Formation in Polycystic Kidney Disease. J. Clin. Invest. 1998; 101(5): 935-939.

https://doi.org/10.1172/JCI2071 
11. Zheleznova NN, Wilson PD, Staruschenko A. Epidermal growth factor-mediated proliferation and sodium transport in normal and PKD epithelial cells'. Biochim Biophys Acta. 2011; 1812(10):1301-13. https://doi.org/10.1016/j.bbadis.2010.10.004

12. Eroglu E, Kocyigit I, Cetin M, Zararsiz G, Imamoglu H, Bayramov R et al. Multiple urinary tract infections are associated with genotype and phenotype in adult polycystic kidney disease. Clin. Exp. Nephrol. 2019; 23(10): 1188-1195. https://doi.org/10.1007/s10157-019-01752-3

13. Wang TZ, Kodiyanplakkal RPL, Calfee DP. Antimicrobial resistance in nephrology. Nat. Rev. Nephrol. 2019; 15: 463-481. https://doi.org/10.1038/s41581-019-0150-7

14. Suwabe T, Araoka H, Ubara Y, Kikuchi K, Hazue R, Mise $\mathrm{K}$ et al. Cyst infection in autosomal dominant polycystic kidney disease: causative microorganisms and susceptibility to lipid-soluble antibiotics. Eur. J. Clin. Microbiol. Infect. Dis. 2015; 34(7): 1369-1379. https://doi.org/10.1007/s10096-015-2361-6

15. Virzi GM, Clementi A, Brocca A, Ronco C. Endotoxin Effects on Cardiac and Renal Functions and Cardiorenal Syndromes. Blood Purif. 2017; 44: 314-326. https://doi.org/10.1159/000480424

16. Lamarche $\mathrm{C}$, Iliuta I-A, Kitzler $\mathrm{T}$. Infectious Disease Risk in Dialysis Patients: A Transdisciplinary Approach. Can. J. Kidney Health Dis. 2019; 6: 1-11. https://doi.org/10.1177/2054358119839080

17. Critical Appraisal Skills Programme. [Homepage of the CASP Critical Appraisal Skills Programme] [online 2021] 2021 last update. [cited 2020 Nov 18]. Available from: https://casp-uk.net/wpcontent/uploads/2018/03/CASP-Case-ControlStudy-Checklist-2018_fillable_form.pdf/

18. Parker MI, Nikonova AS, Sun D, Golemis EA. Proliferative signalling by ERBB proteins and $\mathrm{RAF} / \mathrm{MEK} / \mathrm{ERK}$ effectors in polycystic kidney disease. Cellular Signalling [internet], 2019 [2019/12/09]; $\quad 67(2020)$ : $1-13$. https://doi.org/10.1016/j.cellsig.2019.109497

19. Harskamp LR, Gansevoort RT, van Goor H, Meijer E. The epidermal growth factor receptor pathway in chronic kidney diseases. Nat. Rev. Nephrol. 2016; 12(8): 496-506. https://doi.org/10.1038/nrneph.2016.91

20. Liu W, Fan LX, Zhou X, Sweeney WE, Avner ED, Li X. HDAC6 Regulates Epidermal Growth Factor Receptor (EGFR) Endocytic Trafficking and Degradation in Renal Epithelial Cells. PLOS One [internet], 2012 [2012/11/13]; 7(11): e49418.

https://doi.org/10.1371/journal.pone.0049418

21. Aguiari G, Catizone L, Senno del L. Multidrug Therapy for Polycystic Kidney Disease: A Review and Perspective. Am. J. Nephrol. 2013; 37: 175-182.

https://doi.org/10.1159/000346812

22. Elliott J, Zheleznova NN, Wilson PD. c-Src inactivation reduces renal epithelial cell-matrix adhesion, proliferation and cyst formation. American Journal of Physiology Cell Physiology [internet], 2011 [2011/4/20]; 301(2): C522-C529. https://doi.org/10.1152/ajpcell.00163.2010

23. Coaxum SD, Blanton MG, Joyner A. (2014) Epidermal growth factor-induced proliferation of collecting duct cells from Oak Ridge polycystic kidney mice involves activation of $\mathrm{Na}+\mathrm{H}+$ exchanger. American Journal of Physiology Cell Physiology [internet], 2014 [2014/7/23]; 307(6): C554-C560. https://doi.org/10.1152/ajpcell.00188.2014

24. Sigismund S, Avanzato D, Lanzetti L. Emerging functions of the EGFR in cancer. Mol. Oncol. 2018; 12: 3-20. https://doi.org/10.1002/1878-0261.12155

25. Sweeney WE, Frost P, Avner ED. Tesevatinib ameliorates progression of polycystic kidney disease in rodent models of autosomal recessive polycystic kidney disease. World J. Nephrol. 2017; 6(4): 188-200. https://doi.org/10.5527/wjn.v6.i4.188

26. Clinical Trials: A Safety, Pharmacokinetic and Dose-Escalation Study of KD019 (Tesevaninib) in Subjects with ADPKD. [online] 2020 [cited 2020 Nov 14]. Available from: https://www.clinicaltrials.gov/ct2/show/NCT015 59363/

27. Tesar V, Ciechanowski K, Pei Y, Barash I, Shannon M, Li R et al. Bosutinib versus Placebo for Autosomal Dominant Polycystic Kidney Disease. J. Am. Soc. Nephrol. 2017; 28: 34043413. https://doi.org/10.1681/ASN.2016111232

28. Idrizi A, Barbullushi M, Koroshi A, Dibra M, Bolleku E, Bajrami $\mathrm{V}$ et al. Urinary Tract Infections in Polycystic Kidney Disease. Med. Arch. 2011; 65(4): 213-215.

https://doi.org/10.5455/medarh.2011.65.213-215

29. Gao C, Zhang L, Wallace DP, Lopez-Soler RI, Higgins PJ, Zhang W. Insight into cellular and molecular basis for urinary tract infection in autosomal-dominant polycystic kidney disease. Am. J. Renal Physiol. 2017; 313(5): 1077-1083. https://doi.org/10.1152/ajprenal.00279.2017

30. Hwang JH, Park HC, Jeong JC, ha Baek S, Han MY, Bang K et al. (2013) Chronic asymptomatic 
pyuria precedes overt urinary tract infection and deterioration of renal function in autosomal dominant polycystic kidney disease. BMC Nephrology [internet], 2013 [2013/1/7]; 14:1. https://doi.org/10.1186/1471-2369-14-1

31. Onuchic L, Sato VAH, de Menezes Neves PDM, Balbo BEP, Portela-Neto AA, Ferreira FT et al. Two cases of fungal cyst infection in ADPKD: is this really a rare complication? BMC Infectious Diseases [internet], 2019 [2019/10/29]; 19:911. https://doi.org/10.1186/s12879-019-4444-y

32. Balbo BEP, Sapienza MT, Ono CR, Jayanthi SK, Denttoni JB, Castro I et al. (2014) Cyst infection in hospital-admitted autosomal dominant polycystic kidney disease patients is predominantly multifocal and associated with kidney and liver volume. BJMBR. 2014; 47(7): 584-593.

https://doi.org/10.1590/1414-431X20143584

33. Hjelle JT, Miller-Hjelle MA, Poxton IR, Kajander EO, Ciftcioglu N, Jones ML et al. Endotoxin and nanobacteria in polycystic kidney disease. Kidney Int. 2000; 57(2000); 2360-2374. https://doi.org/10.1046/j.15231755.2000.00096.x

34. Ibrahim M, Behairy M, El-Ashry M, Mostafa AE. Cardiovascular risk of circulating endotoxin level in prevalent hemodialysis patients. Egypt Heart J. 2018; 70(2018): 27-33. https://doi.org/10.1016/j.ehj.2017.06.003

35. Wilson SJ, Amsler K, Hyink DP, Li X, Lu W, Zhou $\mathrm{J}$ et al. Inhibition of HER-2 (neu/ErbB2) restores normal function and structure to polycystic kidney disease (PKD) epithelia. Biochim Biophys Acta. 2006; 1762: 647-655. https://doi.org/10.1016/j.bbadis.2006.04.006

36. Gall EC-L, Audrezet M-P, Chen J-M, Hourmant M, Morin M-P, Perrichot R et al. Type of PKD1 mutation influences renal outcome in ADPKD. J. Am. Soc. Nephrol. 2013; 24(6): 1006-1013. https://doi.org/10.1681/ASN.2012070650

37. Hjelle JT, Miller-Hjelle MA, Nowak DM, Dombrink-Kurtzman MA, Peterson SW. Polycystic kidney disease, fungi, and bacterial endotoxin: shifting paradigms involving infection and diet. Rev. Med. Microbiol. 2000; 11(1): 2335 .

38. Hattar K, Savai R, Subtil FSB, Wilhelm J, Schmall A, Lang DS et al. Endotoxin induces proliferation of NSCLC in vitro and in vivo: role of COX-2 and EGFR activation. Cancer Immunol. Immunother. 2013; 62(2): 309-320. https://doi.org/10.1007/s00262-012-1341-2

39. Tan Y, Blumenfeld J, Rennert H. Autosomal dominant polycystic kidney disease: Genetics, mutations and microRNAs. Biochim Biophys
Acta Mol. Basis Dis. 2011; 1812(10): 1202-1212. https://doi.org/10.1016/j.bbadis.2011.03.002

40. Harris PC. What is the role of somatic mutation in autosomal dominant polycystic kidney disease? J. Am. Soc. Nephrol. 2010; 21(7): 10731076. https://doi.org/10.1681/ASN.2010030328

41. Nguyen, A-N., T., Jansson, K., Sanchez, G. Ouabain activates the Na-K-ATPase signalosome to induce autosomal dominant polycystic kidney disease cell proliferation. Am. J. Physiol. Renal Physiol. 2011; 301(4): F897-F906. https://doi.org/10.1152/ajprenal.00095.2011 
Supplement 1

\begin{tabular}{ll}
\hline Table 1: Key terms used in generic search \\
\hline Key terms & Number of results \\
Polycystic Kidney Disease & 4,897 \\
Epidermal Growth Factor & 51,019 \\
Receptor & \\
Tyrosine Kinase Inhibitor & 60,483 \\
Renal Cyst Formation & 14,199 \\
Renal Cyst Infection & 3,776 \\
\hline
\end{tabular}

Supplement 2

Table 1: Grouping of terms

Grouping of terms

Search strategy (1)

Databases/ No. of papers

identified

PubMed, PubMed Central,

Polycystic Kidney Disease Medline Search

Epidermal growth factor

receptor

Tyrosine kinase inhibitors

Search strategy (2)

Polycystic Kidney Disease

Epidermal Growth Factor

receptor

Revealed 12 papers

2010-2020

PubMed, PubMed Central,

Medline Search

Revealed 21 papers

2010-2020

Cyst formation

Search strategy (3)

Polycystic Kidney Disease

Microbiology

Infection

PubMed, PubMed Central,

Medline Search

Revealed 71 papers

2010-2020

Search strategy (4)

Polycystic Kidney Disease

Microbiology

Antibiotic therapy

PubMed, PubMed Central,

Medline Search

Revealed 32 papers

2010-2020

\section{Supplement 3}

Table 3: Inclusion and exclusion criteria

\begin{tabular}{|c|c|}
\hline Inclusion criteria & Exclusion criteria \\
\hline $\begin{array}{ll}\text { - } & \text { Autosomal dominant PKD } \\
\text { - } & \text { Esearch } \\
\text { Epidermal Growth Factor } \\
\text { - } \quad \text { Tyrosine kinase inhibitor } \\
\text { in ADPKD } \\
\text { - } \quad \text { Studies younger than } 10 \\
\text { - } \quad \text { Sears } \\
\text { - } \quad \text { Studies in English only } \\
\text { cell line and animals/ } \\
\text { animal cell lines } \\
\text { Studies including kidney } \\
\text { cysts, } \\
\text { Studies including cell } \\
\text { biology in PKD } \\
\text { Studies including } \\
\text { molecular biology } \\
\text { Studies including } \\
\text { microbiology } \\
\text { Data collection research } \\
\text { (qualitative and } \\
\text { - } \quad \text { Cohortitative) } \\
\text { Systematic reviews } \\
\text { trials }\end{array}$ & $\begin{array}{l}\text { - } \\
\text { recessive PKD } \\
\text { research } \\
\text { - } \quad \text { Studies older } \\
\text { than } 10 \text { years } \\
\text { Studies in } \\
\text { different } \\
\text { languages than } \\
\text { English } \\
\text { Studies on } \\
\text { hepatic or } \\
\text { pancreatic cysts } \\
\text { Infections in } \\
\text { different organs } \\
\text { than kidneys } \\
\text { Studies on } \\
\text { ErbB2, ErbB3 } \\
\text { and ErbB4 }\end{array}$ \\
\hline
\end{tabular}

